\title{
A new scenario framework for climate change research: the concept of shared socioeconomic pathways
}

\author{
Brian C. O'Neill • Elmar Kriegler • Keywan Riahi • Kristie L. Ebi • \\ Stephane Hallegatte • Timothy R. Carter • Ritu Mathur • Detlef P. van Vuuren
}

Received: 18 January 2013 / Accepted: 28 August 2013 /Published online: 15 October 2013

(C) The Author(s) 2013. This article is published with open access at Springerlink.com

\begin{abstract}
The new scenario framework for climate change research envisions combining pathways of future radiative forcing and their associated climate changes with alternative pathways of socioeconomic development in order to carry out research on climate change impacts, adaptation, and mitigation. Here we propose a conceptual framework for how to define and develop a set of Shared Socioeconomic Pathways (SSPs) for use within the scenario framework. We define SSPs as reference pathways describing plausible alternative trends in the evolution of society and ecosystems over a century timescale, in the absence of
\end{abstract}

This article is part of the Special Issue on "A Framework for the Development of New Socioeconomic Scenarios for Climate Change Research" edited by Nebojsa Nakicenovic, Robert Lempert, and Anthony Janetos.

B. C. O’Neill ( $\square)$

National Center for Atmospheric Research (NCAR), PO Box 3000, Boulder, CO 80305, USA

e-mail: boneill@ucar.edu

E. Kriegler

Potsdam Institute for Climate Impact Research, Potsdam, Germany

K. Riahi

International Institute for Applied System Analysis, Laxenburg, Austria

K. L. Ebi

ClimAdapt, LLC, Los Altos, CA, USA

S. Hallegatte

The World Bank, Washington, DC, USA

T. R. Carter

Finnish Environment Institute (SYKE), Climate Change Programme, Box 140, 00251 Helsinki, Finland

R. Mathur

TERI, New Delhi, India

D. P. van Vuuren

PBL Netherlands Environmental Assessment Agency, Bilthoven, The Netherlands

D. P. van Vuuren

Department of Geosciences, Utrecht University, Utrecht, The Netherlands 
climate change or climate policies. We introduce the concept of a space of challenges to adaptation and to mitigation that should be spanned by the SSPs, and discuss how particular trends in social, economic, and environmental development could be combined to produce such outcomes. A comparison to the narratives from the scenarios developed in the Special Report on Emissions Scenarios (SRES) illustrates how a starting point for developing SSPs can be defined. We suggest initial development of a set of basic SSPs that could then be extended to meet more specific purposes, and envision a process of application of basic and extended SSPs that would be iterative and potentially lead to modification of the original SSPs themselves.

\section{Introduction}

As discussed in van Vuuren et al. (2013), a new framework has been developed to facilitate the production of integrated scenarios based on combinations of climate model projections, socioeconomic conditions, and assumptions about climate policies. A key aim of these integrated scenarios is to facilitate research and assessment across a number of research communities that can characterize the range of uncertainty in mitigation efforts required to achieve particular climate outcomes and in adaptation efforts that could be undertaken to prepare for and respond to the climate changes and impacts associated with those pathways. Many impact and mitigation studies, ranging from global analyses to those that focus on specific regions, sectors, or aspects of climate change, use scenarios either as the basis of their approach or to provide key context information to a more detailed analysis. The new integrated scenarios will provide this information, and the framework will allow analysts to assess a wide range of individual studies by grouping them according to common assumptions they make about socioeconomic conditions or climate change outcomes.

Given these goals, the framework takes the form of a matrix whose dimensions represent key determinants of uncertainty in outcomes. One of those determinants is climate change, since required mitigation effort and adaptation needs will depend strongly on the outcomes to which policy aspires. One axis of the matrix therefore describes climate outcomes, represented by the four alternative Representative Concentration Pathways (RCPs; van Vuuren et al. 2011) and by the climate model projections based on them, which are part of the Coupled Model Intercomparison Project 5 (CMIP-5; Taylor et al. 2011). A second determinant of uncertainty in outcomes is socioeconomic development, since different development pathways can lead to societies that vary widely in drivers of emissions and land use as well as in their capacities to mitigate emissions or undertake adaptation measures. The matrix therefore includes a second axis defined by a set of alternative reference assumptions about future socioeconomic development in the absence of climate policies or climate change, the Shared Socioeconomic Pathways (SSPs). Finally, when SSPs are combined with radiative forcing pathways or climate change outcomes in integrated scenarios, policy assumptions will be necessary in order to produce emissions that would achieve the desired climate outcomes, as well as to characterize adaptation measures. The nature of these policy assumptions is a third key determinant of uncertainty in outcomes, and Shared climate Policy Assumptions (SPAs; Kriegler et al. 2013) define policies that could be assumed in common across studies to support assessment of robust strategies.

The scenario framework is envisioned as being useful to addressing a variety of questions, from investigating in more detail what might constitute dangerous climate change and its dependence on both the level of climate change and future socioeconomic conditions, to evaluation of specific policies, to tradeoffs and synergies between mitigation and adaptation. Several aspects of the SSPs and the general framework are novel compared to the approach in the Special Report on Emissions Scenarios (SRES; Nakicenovic et al. 2000), the previous set of 
scenarios developed for wide use by the climate change research community. First, it updates base year data and trends reflected in previous scenarios. Second, by explicitly aiming to be useful to both mitigation and to adaptation/impacts analysis, it has wider aims than the SRES scenarios, which were designed primarily to span a wide range of emissions. Third, it is designed explicitly to capture uncertainty in climate change outcomes (through the radiative forcing axis) and in socioeconomic pathways relevant to challenges to adaptation and mitigation (through the development pathway axis). Finally, it is designed to be iterative and allow for future development of variants, extensions, and revisions to the initial set of SSPs.

This paper presents the conceptual framework for defining, constructing and using the second axis of the scenario matrix architecture, the SSPs. We first define what SSPs are and what role they play in the matrix architecture, although for a more in-depth discussion of that architecture see van Vuuren et al. (2013) and for an overview of the process undertaken to produce the architecture see Ebi et al. (2013). We then discuss the logic used to construct SSPs, which begins with the space of possible futures that the set of SSPs is intended to span. Although in this paper we do not define the content of the SSPs (i.e., we do not actually describe specific alternative development pathways), we discuss the types of elements of socioeconomic and environmental systems that might be used to specify particular SSPs, including demographic, economic, institutional, and other dimensions. We distinguish two variants of SSPs - basic vs. extended that provide different levels of detail about future development pathways. Finally, we provide an illustration of the SSP concept by revisiting the choices made in SRES, sketching illustrative starting points for SSP narratives, and noting the relation of these narratives to the SRES scenarios.

\section{The definition of SSPs}

The SSPs describe plausible alternative trends in the evolution of society and natural systems over the 21 st century at the level of the world and large world regions. They consist of two elements: a narrative storyline and a set of quantified measures of development. SSPs are "reference" pathways in that they assume no climate change or climate impacts, and no new climate policies (Kriegler et al. 2012). The choice to define SSPs in this way was made in order to serve a methodological purpose. The ultimate goal of the overall scenario process is to produce integrated scenarios that will indeed include socioeconomic and environmental conditions as affected by both climate change and climate policy. As described in section 1, evaluating climate change impacts on society and the consequences of alternative policy approaches are key goals of the scenario framework. SSPs are a step along the way toward these goals. The intention is that by not incorporating such effects, SSPs can be more easily used by other researchers across a broad set of studies to evaluate how varying levels of climate change and types of policies affect on the "reference" socioeconomic and environmental conditions described in the SSPs. Because SSPs do not include the effects of climate change and climate policy, they may not describe plausible assumptions for the future, but this is an intentional component of the design.

In addition, the set of quantitative elements included in SSPs does not extend to outcomes such as emissions and land use that are typically calculated by integrated assessment models, or to outcomes of impact models such as effects on agriculture. SSPs include quantifications of factors that are considered drivers of such outcomes such as population growth and economic growth, but quantification of the consequences of these drivers is left to scenarios that will be produced based on the SSPs (van Vuuren et al. 2013). It is for this reason that the scenario framework distinguishes between "pathways," which describe one component (such as RCPs 
or SSPs) of integrated scenarios, and "scenarios" themselves, which combine pathways with other information such as emissions, climate projections and policy assumptions to produce integrated descriptions of future climate and human system development. It is these scenarios, rather than the SSPs themselves, that would be used to do analysis such as comparing outcomes in a policy scenario with outcomes in a reference (no-policy) scenario.

\section{The logic behind the choice of the SSPs}

A key question is how a limited set of SSPs can be chosen to most effectively serve the goals of the scenario matrix architecture. In principle, two approaches can be taken. One is a forward approach, in which a small number of key socioeconomic drivers are combined into a set of plausible pathways highlighting the different directions in which the world may evolve. This approach has been frequently adopted in the past, for example in the SRES scenarios (Nakicenovic et al. 2000) and in the Millennium Ecosystem Assessment (MA; Bennett et al. 2005). Another is an inverse approach, in which one begins with the outcomes of interest for climate change research and then identifies combinations of key socioeconomic drivers that are likely to produce those outcomes. This approach has also been used previously, for example in scenarios for achieving global sustainability (Raskin et al. 1998), particular types of climate goals (Toth 2003), or sustainable energy transitions (Riahi et al. 2012).

Both approaches are complementary and indeed both contribute to the formulation of the SSPs. However, we have chosen to start the process with the inverse approach in order to ensure that the choice of SSPs produces a set of development pathways that is as relevant as possible to the goal of the scenario framework, which as discussed in section 1 is to explore uncertainty in mitigation, adaptation, and impacts associated with alternative climate and socioeconomic futures. A discussion of key socioeconomic elements and drivers that, in a second step, can be combined to create SSPs (i.e., the forward approach) is provided in the next section.

To help ensure that the set of SSPs developed actually spans a range of outcomes that will allow the characterization of uncertainty in mitigation, adaptation, and impacts, we define an outcome space in which socioeconomic and environmental challenges are represented on two axes: one axis depicts challenges pertaining to adaptation; the other axis challenges to mitigation (Fig. 1). The logic here is that for characterizing uncertainties in the implications of mitigating climate change to a given level, or of adapting to that level (key goals of the scenario framework), we need to describe future socioeconomic conditions that would make mitigation and adaptation relatively hard or relatively easy. In the figure axes, and in the text, "socioeconomic" is intended to be shorthand for a wide range of aspects of society or, more broadly, socioecological systems. These include demographic, political, social, cultural, institutional, life-style, economic, and technological aspects, and the conditions of ecosystems and ecosystem services that have been affected by human activity such as air and water quality, biodiversity, and ecosystem form and function. The intention of this "socioeconomic" label is primarily to communicate that we exclude conditions related to future climate change itself. This applies to ecological variables (such as biodiversity) just as much as it does to economic or other variables relating more directly to society. Although climate change and biodiversity in reality interact, the SSP describes a hypothetical future in which biodiversity is not affected by further climate change, so that scenarios can then be developed to estimate the effect of future climate change on biodiversity (among other things).

This "challenges space" is conceptually quite different from typical two-axes approaches to defining the space to be explored in forward scenarios, as for example in the SRES and Millennium Assessment scenarios. In those cases, the axes were defined by two key socio- 


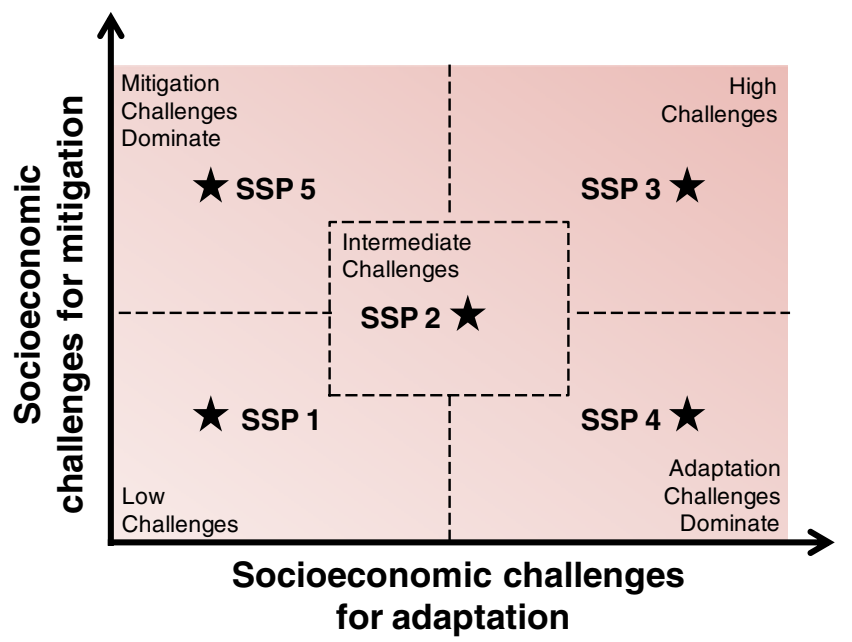

Fig. 1 The "challenges space" to be spanned by SSPs (based on Kriegler et al. 2012, Fig. 3), divided into five "domains" with one SSP located within each domain, represented by a star

economic driving forces that were assumed to be principal uncertainties determining outcomes of interest. Here, we use the outcomes of interest themselves to define the axes. We introduce this outcome space as part of the inverse approach to pathway construction in order to explicitly guide the process of developing SSPs toward producing a set that spans the space of interest and to provide a way to check whether this goal has been achieved once SSP development is complete. In this sense, the guidance of SSP construction by locating them in the challenge spaces, and their actual construction by combining assumptions about key socioeconomic drivers, are complementary.

\subsection{Challenges to mitigation}

Challenges to mitigation for the purpose of defining SSPs do not include the stringency of the mitigation target itself or the choice of mitigation action, which are accounted for by two other aspects of the scenario matrix: the forcing level of the representative concentration pathway (RCP) and the shared policy assumption (SPA), respectively. Rather, these challenges are defined by socioeconomic factors that would make the mitigation task easier or harder for any given target and mitigation policy.

Socioeconomic challenges to mitigation are defined as consisting of: (1) factors that tend to lead to high reference emissions in the absence of climate policy because, all else equal, higher reference emissions makes that mitigation task larger; and (2) factors that would tend to reduce the inherent mitigative capacity of a society. High reference emissions could be generated in a large number of ways, with possible contributions from high population growth rates, rapid economic growth, extensive land use, energy intensive economic systems, and carbon intensive energy supplies. More fundamental processes could drive each of these factors, such as technological and social changes that include (autonomous) energy efficiency improvements, fossil fuel availability, and dietary choices. An SSP would include assumptions about particular combinations of emissions drivers.

As discussed above, model outcomes such as emissions should be part of scenarios based on SSPs, rather than part of SSPs themselves, which emphasize development pathways and drivers. Yet the definition of challenges to mitigation includes outcomes, in particular high 
or low reference emissions. Thus a balance must be struck in designing SSPs by having outcomes in mind when designing assumptions about the determinants of emissions while avoiding the outright specification of outcomes. It is likely that some iteration between the design of SSPs and the development of scenarios based on them will be necessary before the set of SSPs and reference scenarios is developed that most effectively spans the space of future outcomes.

Factors that tend to influence the mitigative capacity of a society include the range of viable technological options, national and international institutions for policy making, the availability of financial resources necessary to support mitigation activities, stocks of human and social capital, and political will for addressing energy and environmental issues (Yohe 2001; Winkler et al. 2007; Klein et al. 2007). High (or low) mitigative capacity can result from the combination of a limited set of these factors, and need not involve all factors influencing capacity in the same direction. It also may be the case that key determinants of mitigative capacity, including the capacity for technological change in energy systems, overlap significantly with determinants of reference emissions, making these two components of challenges to mitigation closely related. A key task for developing SSPs will be to choose assumptions about the factors contributing to mitigative capacity that are (1) likely to produce the desired degree of challenge to mitigation, (2) consistent with assumptions about factors leading to the desired degree of challenge to adaptation, and (3) consistent with the overall logic of the particular development pathway being described.

\subsection{Challenges to adaptation}

Socioeconomic challenges to adaptation are defined as societal or environmental conditions that, by making adaptation more difficult, increase the risks associated with any given projection of climate change. Climate change risks arise from the combination of climate hazards (or physical impacts of climate change) such as sea level rise, changes in temperature and precipitation, and extreme events; who or what is exposed to those hazards; and their propensity to adverse impacts, whether it is geographic, socioeconomic, cultural, etc. (see Rothman et al. 2013, for a discussion of how challenges to adaptation relate to concepts in the impacts, adaptation, and vulnerability literature). Within the scenario matrix architecture, the component of climate change risk due to physical impacts of climate change is reflected in climate model projections based on the RCPs and therefore should not be contained in the SSPs. The remaining components of risk are inherent to human-environment systems potentially exposed to those hazards, and therefore are appropriately included in the SSPs. Challenges to adaptation are a function of the socioeconomic determinants of exposure to climate change hazards, sensitivity to these hazards, and the adaptive capacity to deploy coping measures. They include the limits of autonomous adaptation (i.e., the range of adaptive measures that are readily accessible to individuals and organizations) and the obstacles and constraints to adaptation policies, such as ineffective institutions and governance that impede policy implementation.

Exposure is the presence of people; livelihoods; infrastructure; ecosystem services and resources; and economic, social, and cultural assets in places that could be adversely affected by a climate hazard. For example, a population that is concentrated near a coastline has potentially high exposure to the impacts of sea level rise, while one that is heavily concentrated in urban areas has potentially high exposure to urban heat waves. Sensitivity, which is sometimes intertwined with exposure, indicates the responsiveness of socioeconomic systems to a given amount of climate change; it can be described by an exposure-response relationship. If coastal populations live in poorly constructed housing, for example, they would be more sensitive to the increased storm surges associated with sea level rise compared to a population living in better-constructed 
buildings. Likewise, an urban population that has higher proportions of elderly residents, who are physiologically more susceptible to extreme conditions than most of the remaining population, would be more sensitive to urban heat waves.

Adaptive capacity indicates the ability of a society to adjust to climate change in order to ameliorate its consequences or to take advantage of opportunities. Factors that influence this capacity include the availability of viable technological options for adaptation, the effectiveness of relevant institutions (such as agricultural research and development, markets for goods affected by climate change, forest management organizations, etc.), and the availability of human and financial resources, including their distribution across the population (Klein et al. 2007; Yohe and Tol 2002; Hallegatte et al. 2011). For example, a well functioning public health system would increase the capacity of a society to ameliorate health impacts of heat waves, while well functioning food markets and institutions for agricultural research and development would increase the capacity to ameliorate consequences of climate change for agriculture, including the possibility of taking advantage of outcomes such as lengthening growing seasons and higher $\mathrm{CO}_{2}$ concentrations that could be beneficial to some crops.

\subsection{Domains within the challenges space}

Figure 1 shows the challenges space divided into five domains with different combinations of socioeconomic challenges to mitigation and adaptation. Domain 1 in the lower left corner, for example, indicates a future in which challenges to both mitigation and adaptation are low. By contrast, Domain 3 indicates a future in which challenges to both are high. Different socioeconomic pathways could produce outcomes that fall within any of these domains, and many different pathways could fall within a given domain. The Shared Socio-economic Pathways (SSPs) are indicated by stars that represent a single socioeconomic pathway within each domain developed for common use across a wide range of studies within the overall scenario framework. The number and location of these domains are for illustrative purposes; the most appropriate number and characterization of the SSPs remain to be decided by the scientific community.

The time dimension is not explicitly indicated in Fig. 1, but the domains are intended to contain pathways that evolve over time. The two axes therefore represent challenges that can change over time and are defined in relative terms. That is, challenges to mitigation, or adaptation, mean challenges relative to a middle-of-the-road outlook for how such challenges may evolve over time. Thus, Domain 2 captures the location of socioeconomic pathways situated towards the center of the distribution of plausible outcomes for the challenges to mitigation and adaptation as they develop into the future. This does not imply that the challenges are static in Domain 2. They would be expected to change in an absolute sense over time consistent with middle-of-the-road development. Current expectations would likely be that future societies might have larger challenges to mitigation, but smaller challenges to adaptation, than current societies, given anticipated increases in emissions (in the absence of mitigation policy) as well as in incomes and human capital development, although we consider this a hypothesis rather than an established fact.

An important question is whether some of the domains in this challenges space are a higher priority to explore than others, and if so, for which purpose. For example, domains 1-3, lying along the diagonal from the lower left to upper right, represent futures in which socioeconomic challenges to mitigation co-vary with challenges to adaptation. In contrast, domains 4 and 5 indicate futures in which challenges are high to either mitigation, or to adaptation, but not both. It is possible that the drivers of these challenges are more likely to co-vary, which would favor focusing on the SSPs along the diagonal, but this question remains to be explored. In many cases, the determinants of mitigative and adaptive capacity are similar and can be conceptualized as a 
more general "response capacity" (Klein et al. 2007; Tompkins and Adger 2005). For example, human and social capital are important determinants for both, and the broader concept of resilience may be quite relevant here as well (Miller et al. 2010). On the other hand, these capacities need not share the same determinants (Hallegatte et al. 2011), because (for example) institutions important to adaptation challenges, such as disaster relief organizations and agricultural extension services, are not necessarily the same ones that are important to mitigation challenges. Furthermore the challenges to mitigation and adaptation as conceptualized here include not just response capacity, but also other elements of development pathways such as those that would lead to high reference emissions or to high levels of sensitivity to climate change.

\subsection{Domains, socioeconomic pathways, and SSPs}

In principle, all possible socioeconomic development pathways could be mapped to the challenges space, and any given domain of that space could contain a very large number of such pathways. The set of SSPs is intended to consist of a single pathway from each domain that is developed in order to be widely shared across research groups and studies in order to improve consistency and comparability of results and facilitate assessment of the literature produced. This approach keeps the number of socioeconomic pathways manageable, at the risk of appearing to simplify the complexity of drivers of mitigative and adaptive capacity (Rozenberg et al. 2013).

A further consideration is that the SSP should set the boundary conditions within which regional and sectoral variation could occur. For example, some pathways might envision response capacities that are low in some parts of the world and high in others, or that transition from one state to another over time. An additional consideration is that some futures may not be the most plausible outcomes, but nonetheless may be equally (or even more) important to explore given their potential consequences.

\section{Characteristics and elements of the SSPs}

Although the SSPs are differentiated on the basis of pre-specified outcomes, specifically socioeconomic challenges to adaptation and to mitigation, they are constructed from determinants of these outcomes (e.g. population, economic development, technologies, preferences, institutional effectiveness). Some of these elements will be expressed qualitatively in narratives, while others will be quantitative. Developing a list of SSP elements begins with defining desirable characteristics of the set of SSPs that would make them as useful as possible within the overall scenario framework.

SSPs have the following key characteristics:

1. A focus on the description of socioeconomic and environmental trends at the level of the world and large world regions, and over the 21 st century.

2. Qualitative and quantitative content sufficient to distinguish SSPs from each other in terms of their challenges to mitigation and adaptation.

3. Incorporation of information typically used as input assumptions by integrated assessment models of the global energy-economy-land use system, or by global-scale climate impact models of different sectors. At a minimum, this includes assumptions about future demographics, economic development, and degree of global integration. Such assumptions will likely involve quantitative pathways for population and economic development. SSPs should generally not contain information that would typically be 
outcomes of such models, such as the precise mix of technologies used in the energy sector, specific emissions or land use outcomes, climate change and its implications for agriculture.

4. Restriction to assumptions that do not include policies and measures directly motivated by climate change, or their effects on other variables. An SSP refers to socioeconomic reference development of a world without future climate policy and without climate change. The dividing line between climate policies and other policies can sometimes be difficult to draw; useful approaches are discussed in Kriegler et al. (2013), including how to treat currently implemented climate policy measures.

5. Information sufficient to support elaboration or extension of global assumptions to local- and regional-scale scenarios.

Based on these characteristics of an SSP, a number of possible elements have been discussed at meetings and workshops related to the scenario process (see also van Vuuren et al. 2012; Kriegler et al. 2012) that will interact with each other to produce development pathways and be relevant to defining challenges to mitigation and adaptation, and are shown in Table 1. This list is not exhaustive nor does it reflect prioritization. A variety of other approaches have been taken to identifying and prioritizing key elements of SSPs (Schweizer and O’Neill 2013; Rozenberg et al. 2013).

\section{Basic vs. Extended SSPs}

The development of SSPs is proposed to take place in two stages. A first stage would define basic SSPS with the minimum detail and comprehensiveness required to distinguish SSPs in terms of challenges to mitigation and adaptation as described in section 3 and to provide useful input to impact and integrated assessment models, particularly analyses at global or large regional scales. A second stage would develop extended SSPS that build on the basic SSPs by providing more detailed qualitative and/or quantitative information to support more specific sectoral and regional analyses. The elements that would be included in basic vs. extended SSPs remain to be defined. We hypothesize that each of the nine categories of SSP elements in section 3 should be included to some extent in basic SSPs, but the degree of detail that is necessary within each category and at what spatial or temporal resolution, or whether additional categories are required, remain open questions.

The two primary motivations for this two-stage approach are practicality and flexibility. A minimum set of assumptions can be defined more quickly and therefore can be available for use sooner, increasing the potential for carrying out analyses based on the new SSPs that could be assessed as part of an iterative, longer-term scenario process. Basic SSPs also offer the possibility for experimentation by a wide range of researchers on extending the basic SSPs in various dimensions. These extensions could be motivated by a number of different needs.

- Experience with developing scenarios based on basic SSPs may lead to a need for additional information by particular models (or types of models) that is not contained in the basic SSPs. For example, this information might include more detail on consumption patterns, income distributions, non-climate-related policies, or specific development strategies.

- Application of basic SSPs in regional and local contexts will likely lead to new demands for information that will make the SSPs more useful for decision-makers at those scales. One can view basic SSPs as describing "boundary conditions" that provide the framing 
Table 1 Possible elements of SSPs relevant to defining challenges to mitigation and adaptation

\begin{tabular}{|c|c|}
\hline Category & Scenario element \\
\hline Demographics & $\begin{array}{l}\text { - Population total and age structure } \\
\text { - Urban vs. rural populations, and urban forms } \\
\text { - Other location information, such as coastal vs. inland }\end{array}$ \\
\hline Economic development & $\begin{array}{l}\text { - Global and regional GDP, or trends in productivity } \\
\text { - Regional, national, and sub-national distribution of GDP, including economic } \\
\text { catch-up by developing countries } \\
\text { - Sectoral structure of national economies, in particular the share of agriculture, } \\
\text { and agricultural land productivity } \\
\text { - Share of population in extreme poverty } \\
\text { - Nature of international trade }\end{array}$ \\
\hline Welfare & $\begin{array}{l}\text { - Human development } \\
\text { - Educational attainment } \\
\text { - Health, including access to public health and health care infrastructure }\end{array}$ \\
\hline $\begin{array}{l}\text { Environmental and } \\
\text { ecological factors }\end{array}$ & $\begin{array}{l}\text { - Air, water, soil quality } \\
\text { - Ecosystem functioning }\end{array}$ \\
\hline Resources & $\begin{array}{l}\text { - Fossil fuel resources and renewable energy potentials } \\
\text { - Other key resources, such as phosphates, fresh water etc. }\end{array}$ \\
\hline Institutions and governance & $\begin{array}{l}\text { - Existence, type and effectiveness of national/regional/global institutions } \\
\text { - Degree of participation } \\
\text { - Rule of law }\end{array}$ \\
\hline Technological development & $\begin{array}{l}\text { - Type (e.g. slow, rapid, transformational) and direction (e.g. environmental, } \\
\text { efficiency, productivity improving) of technological progress } \\
\text { - Diffusion of innovation in particular sectors, e.g. energy supply, distribution } \\
\text { and demand, industry, transport, agriculture }\end{array}$ \\
\hline Broader societal factors & $\begin{array}{l}\text { - Attitudes to environment/sustainability/equity and world views } \\
\text { - Life styles (including diets) } \\
\text { - Societal tension and conflict levels }\end{array}$ \\
\hline Policies & $\begin{array}{l}\text { - Non-climate policies including development policies, technology policies, } \\
\text { urban planning and transportation policies, energy security policies, and } \\
\text { environmental policies to protect air, soil and water quality. It is possible that } \\
\text { SSPs could be specified partly in terms of policy objectives, such as strong } \\
\text { welfare-improving goals, rather than specific policy targets or measures. }\end{array}$ \\
\hline
\end{tabular}

for more specific assumptions for regions or sectors, including additional elements of narratives, which could then become part of extended SSPs.

A large number of extended SSPs could be constructed for any given basic SSP. A hierarchical structure comprising a small number of basic SSPs, each associated with a family of extended SSPs, may be useful. For example, it may facilitate structured uncertainty analysis. A family of extended SSPs could reflect the range of assumptions that are consistent with a given basic SSP and that are requested as additional inputs for the construction of socioeconomic reference scenarios (e.g. in integrated assessment models or in sectoral and regional studies). Such extensions could help to define the range of socioeconomic reference scenarios that can be associated with a basic SSP. Combining the family of extended SSPs with climate policy assumptions would also help to investigate the robustness of the climate policy scenarios across the SSP family. 
A possible drawback to the development of a large number of extended SSPs is that it could blur the distinction between SSPs and scenarios. To the degree that extended SSPs become associated with individual model interpretations of an SSP, this distinction becomes less clear. An alternative would be to aim for the development of a small number of extended SSPs for each basic SSP, each of which extends the basic SSP in somewhat different directions, but remains broad enough to support the development of a large number of scenarios based on each extended SSP.

The development of basic and extended SSPs does not preclude producing revised versions of either. After a period of time, assumptions in even the basic SSPs may become outdated or for other reasons require revision; at that time, a second generation of SSPs could be produced.

\section{Initial specification of SSPs}

Specification of the SSPs could proceed by first defining qualitative narratives describing broad development pathways hypothesized to produce the desired combinations of challenges to mitigation and adaptation, sketch qualitative trends in key SSP elements, and then quantify those elements deemed most useful to represent in quantitative form. A number of different approaches could be taken to identifying narratives and important SSP elements that have the potential to produce internally consistent pathways that achieve the desired outcomes in terms of challenges to mitigation and adaptation, including elicitation of experts (Schweizer and O'Neill 2013), generation of large numbers of candidate pathways (Rozenberg et al. 2013; Schweizer and O'Neill 2013), or group consensus processes.

The IPCC SRES provides an example of the types of information that are likely to be useful to include in SSPs. The SRES developed four families of socioeconomic futures that span the dimensions of globalized vs. regionalized development and economic vs. environmental orientation. A similar specification of narratives for the SSPs will be needed in an early phase of SSP construction. The narratives should be chosen such that they cover the space of socioeconomic challenges to mitigation and adaptation (Section 3). Table 2 is an illustration of a starting point for such narratives. It is important to note that we are not advocating for a specific number or content of SSPs, nor that the SSPs should be based on previously existing scenarios such as SRES. The objective of this paper is to suggest a framework for the construction of new socioeconomic pathways. The actual formulation of the SSPs and scenarios based on them are to be a community activity based on this framework.

Associated with such narrative starting points, identifying qualitative trends for various SSP elements can help sketch out the major dimensions of development pathways for a given SSP and their differences across SSPs. Such an approach to describing storylines was used in the development of scenarios to explore the possibilities and challenges related to global sustainability transitions (Gallopin et al. 1997; NRC 1999). Combinations of such trends would need to be developed through a collaborative process including experts in integrated assessment modeling, impacts and adaptation, and other relevant disciplines, with care taken to ensure the internal consistency of pathways taken as a group, keeping in mind the intended part of the space of future challenges to adaptation and mitigation to be covered.

Further decisions will be needed about which types of information within an SSP should be qualitative and which quantitative. Designers of SSPs will need to balance the competing goals of limiting the quantification in SSPs in order to allow for scenarios based on them to fully explore relevant uncertainties and providing enough quantitative constraints on outcomes so that scenarios remain within the intended domain of the challenges space. The list of possible elements in Table 1 provides a starting point for these considerations. While it is likely that broad features of 
Table 2 Initial starting points for SSP narratives, based on Kriegler et al (2012). SRES analogues are based on comparison of storylines only. See van Vuuren and Carter (2013) for a more thorough assessment of analogues to existing scenarios

\begin{tabular}{|c|c|c|c|}
\hline SSP 1 & $\begin{array}{c}\text { Low for mitigation } \\
\text { and adaptation }\end{array}$ & $\begin{array}{l}\text { Sustainable development proceeds at a reasonably high pace, } \\
\text { inequalities are lessened, technological change is rapid and } \\
\text { directed toward environmentally friendly processes, } \\
\text { including lower carbon energy sources and high } \\
\text { productivity of land. }\end{array}$ & $\mathrm{B} 1, \mathrm{~A} 1 \mathrm{~T}$ \\
\hline SSP2 & Moderate & An intermediate case between SSP1 and SSP3. & \\
\hline SSP 3 & $\begin{array}{l}\text { High for mitigation } \\
\text { and adaptation }\end{array}$ & $\begin{array}{l}\text { Unmitigated emissions are high due to moderate economic } \\
\text { growth, a rapidly growing population, and slow } \\
\text { technological change in the energy sector, making } \\
\text { mitigation difficult. Investments in human capital are low, } \\
\text { inequality is high, a regionalized world leads to reduced } \\
\text { trade flows, and institutional development is unfavorable, } \\
\text { leaving large numbers of people vulnerable to climate } \\
\text { change and many parts of the world with low adaptive } \\
\text { capacity. }\end{array}$ & A2 \\
\hline SSP 4 & $\begin{array}{l}\text { High for adaptation, } \\
\text { low for mitigation }\end{array}$ & $\begin{array}{l}\text { A mixed world, with relatively rapid technological } \\
\text { development in low carbon energy sources in key emitting } \\
\text { regions, leading to relatively large mitigative capacity in } \\
\text { places where it mattered most to global emissions. } \\
\text { However, in other regions development proceeds slowly, } \\
\text { inequality remains high, and economies are relatively } \\
\text { isolated, leaving these regions highly vulnerable to climate } \\
\text { change with limited adaptive capacity. }\end{array}$ & No analogue \\
\hline
\end{tabular}

demographic and economic development futures should be included in quantitative form, many choices remain regarding the assumptions to be made in other areas.

\section{Discussion and conclusions}

This paper has described a conceptual framework for a set of Shared Socioeconomic Pathways (SSPs) as part of an overall scenario matrix architecture for developing and applying new integrated scenarios for climate change research. The SSPs differ from many previous approaches to socioeconomic scenario development in a few ways that are worth emphasizing. The development process combines both inverse and forward approaches in a complementary manner, beginning with defining an outcome space to be spanned describing combinations of challenges to adaptation and mitigation, and then identifying combinations of socioeconomic trends that are hypothesized to lead to those outcomes. Furthermore, because the SSPs are one part of a larger framework for scenario development, they represent reference conditions that do not include elements that will be the objects of study of the overall framework, namely emissions, land use, 
climate change, its impacts, and climate policy responses. As a consequence, the SSPs should be seen as hypothetical development pathways that serve as a starting point for developing integrated scenarios of the future, rather than as plausible scenarios themselves.

The SSPs, combined with the scenario matrix architecture, provide a flexible tool for climate change research. They can be applied as boundary conditions to studies in more specific geographical or sectoral contexts, narratives can be extended to suit the needs of specific studies, and additional quantitative information can be added as needed. In addition, SSPs are only examples of the kinds of socioeconomic futures that can produce particular challenges to adaptation and mitigation. To explore uncertainty in ways these challenges might be achieved, SSP variants should be developed, or even entirely new pathways that produce challenges in fundamentally new ways.

Employing this framework to develop SSPs will require the participation of researchers from many different communities, with collaboration between the IAM and IAV communities being particularly important. Critical next steps include defining the number and content of the basic SSPs, which will involve the development of narratives and the quantification of key SSP elements. Here we offered an illustration of a starting point for SSP narratives. A much larger process, with substantial input from different communities, is already underway to define SSP narratives and quantitative information (O’Neill et al. 2012). Once basic SSPs have been developed, it will be possible both to begin applying them in research studies and integrated scenario development, and also to establish a process for producing extended versions of the SSPs to meet specific needs for analyses of particular sectors, regions, or response options. This process should be open and flexible, allowing not only for extended SSPs but also revisions to them as experience is gained.

Open Access This article is distributed under the terms of the Creative Commons Attribution License which permits any use, distribution, and reproduction in any medium, provided the original author(s) and the source are credited.

\section{References}

Bennett E, Carpenter S, Cork S, Peterson G, Petschel-Held G, Ribeiro T, Zurek M (2005) Scenarios for ecosystem services: rationale and overview. In: Carpenter SR, Pingali PL, Bennett EM, Zurek MB (eds) Ecosystems and human well-being: scenarios, vol 2. Island Press, Washington

Ebi KL, Hallegatte S, Kram T, Arnell NW, Carter TR, Edmonds J, Kriegler E, Mathur R, O’Neill BC, Riahi K, Winkler H, van Vuuren DP, Zwickel T (2013) A new scenario framework for Climate Change Research: background, process, and future directions. Climatic Change, Special Issue, Nakicenovic N, Lempert R, Janetos A (eds) A Framework for the Development of New Socioeconomic Scenarios for Climate Change Research

Gallopin G, Hammond A, Raskin P, Swart R (1997) Branch points: global scenarios and human choice. PoleStar Series Report, 7. Stockholm Environment Institute, Stockholm

Hallegatte S, Przyluski V, Vogt-Schilb A (2011) Building world narratives for climate change impact, adaptation and vulnerability analyses. Nature Clim Change 1(3):151-155

Klein RJT, Huq S, Denton F, Downing TE, Richels RG, Robinson JB, Toth FL (2007) In: Parry ML, Canziani OF, Palutikof JP, van der Linden PJ, Hanson CE (eds) Inter-relationships between adaptation and mitigation. Climate change 2007: impacts, adaptation and vulnerability. Contribution of working group II to the fourth assessment report of the intergovernmental panel on climate change. Cambridge University Press, Cambridge, pp 745-777

Kriegler E, O’Neill BC, Hallegatte S, Kram T, Lempert R, Moss R, Wilbanks T (2012) The need for and use of socio-economic scenarios for climate change analysis: a new approach based on shared socioeconomic pathways. Global Environmental Change 22:807-822

Kriegler E, Edmonds J, Hallegatte S, Ebi K, Kram T, Riahi K, Winkler H, van Vuuren D (2013) A new scenario framework for Climate Change Research: the concept of shared policy assumptions. Climatic Change, Special Issue, Nakicenovic N, Lempert R, Janetos A (eds) A Framework for the Development of New Socioeconomic Scenarios for Climate Change Research 
Miller F, Osbahr H, Boyd E, Thomalla F, Bharwani S, Ziervogel G, Walker B, Birkmann J, Van der Leeuw S, Rockström J, Hinkel J, Downing T, Folke C, Nelson D (2010) Resilience and vulnerability: complementary or conflicting concepts? Ecology and Society 15(3):11

Nakicenovic N, Alcamo J, Davis G, de Vries B, Fenham J, Gaffin S, Gregory K, Gruebler A, Jung TY, Kram T, La Rovere EL, Michaelis L, Mori S, Morita T, Pepper W, Pitcher H, Price L, Riahi K, Roehrl A, Rogner H-H, Sankovski A, Schlesinger M, Shukla P, Smith S, Swart R, van Rooijen S, Victor N, Dadi Z (2000) Special report on emissions scenarios. Cambridge University Press, New York

National Research Council (NRC) Board on Sustainable Development (1999) Our common journey: a transition toward sustainability. The National Academies Press, Washington, DC

O’Neill BC, Carter TR, Ebi KL, Edmonds J, Hallegatte S, Kemp-Benedict E, Kriegler E, Mearns L, Moss R, Riahi K, van Ruijven B, van Vuuren D (2012) Meeting Report of the Workshop on The Nature and Use of New Socioeconomic Pathways for Climate Change Research, Boulder, CO, November 2-4, 2011. Available at: http://www.isp.ucar.edu/socio-economic-pathways

Raskin P, Gallopin G, Gutman P, Hammond A, Swart R (1998) Bending the curve: toward global sustainability. Stockholm Environment Institute, Stockholm

Riahi K, Dentener F, Gielen D, Grubler A, Jewell J, Klimont Z, Krey V, McCollum D, Pachauri S, Rao S, van Ruijven B, van Vuuren DP, Wilson C (2012) Chapter 17 - Energy pathways for sustainable Development. In global energy assessment - toward a sustainable future, Cambridge University Press, Cambridge, UK and New York, NY, USA and the International Institute for Applied Systems Analysis, Laxenburg, Austria, pp. 1203-1306

Rothman DS, Romero-Lankao P, Schweizer VJ, Bee BA (2013) Challenges to adaptation: A fundamental concept for the Shared Socioeconomic Pathways and beyond. Climatic Change, Special Issue, Nakicenovic N, Lempert R, Janetos A (eds) A Framework for the Development of New Socio-economic Scenarios for Climate Change Research

Rozenberg J, Guivarch C, Lempert R, Hallegatte S (2013) A scenario elicitation methodology to map the space of possible future mitigative and adaptive capacity. Climatic Change, Special Issue, Nakicenovic N, Lempert R, Janetos A (eds) A Framework for the Development of New Socioeconomic Scenarios for Climate Change Research

Schweizer V, O’Neill BC (2013) Internally consistent combinations of SSP narrative elements. Climatic Change, Special Issue, Nakicenovic N, Lempert R, Janetos A (eds) A Framework for the Development of New Socioeconomic Scenarios for Climate Change Research

Taylor KE, Stouffer RJ, Meehl GA (2011) An overview of CMIP5 and the experiment design. Bull Amer Meteor Soc. doi:10.1175/BAMS-D-11-00094.1

Tompkins EL, Adger WN (2005) Defining response capacity to enhance climate change policy. Environ Sci Pol 8:562-571

Toth F (2003) Integrated assessment of climate protection strategies: guest editorial. Climatic Change 56:1-5

Van Vuuren DP, Edmonds J, Thomson A, Riahi K, Kainuma M, Matsui T, Hurtt GC, Lamarque J-F, Meinshausen M, Smith S, Granier C, Rose SK, Hibbard KA (2011) Representative concentration pathways: an overview. Climatic Change 109:5-31

van Vuuren DP, Riahi K, Moss R, Edmonds J, Thomson A, Nakicenovic N, Kram T, Berkhout F, Swart R, Janetos A, Rose SK, Arnell A (2012) A proposal for a new scenario framework to support research and assessment in different climate research communities. Global Environmental Change 22:21-35

van Vuuren DP, Kriegler E, O’Neill BC, Ebi KL, Riahi K, Carter TR, Edmonds J, Hallegatte S, Kram T, Mathur R, Winkler H (2013) A new scenario framework for Climate Change Research: scenario matrix architecture. Climatic Change, Special Issue, Nakicenovic N, Lempert R, Janetos A (eds) A Framework for the Development of New Socioeconomic Scenarios for Climate Change Research

van Vuuren DP, Carter TR (2013) Climate and socio-economic scenarios for climate change research and assessment: reconciling the new with the old. Climatic Change, Special Issue, Nakicenovic N, Lempert R, Janetos A (eds) A Framework for the Development of New Socioeconomic Scenarios for Climate Change Research

Winkler H, Baumert K, Blanchard O, Burch S, Robinson J (2007) What factors influence mitigative capacity? Energy Policy 35(1):692-703

Yohe GW (2001) Mitigative capacity - the mirror image of adaptive capacity on the emissions side. Climatic Change 49(3):247-262

Yohe G, Tol RSJ (2002) Indicators for social and economic coping capacity — moving toward a working definition of adaptive capacity. Global Environmental Change 12(1):25-40 